\title{
Simulation of Electrical Characteristics of Switching Nanostructures "Pt - TiO - Pt" and "Pt - NiO - Pt" with Memory
}

\author{
Daulet SERGEYEV ${ }^{1,2}$, Nurgul ZHANTURINA ${ }^{1}$ \\ ${ }^{1}$ Dept. of Physics, K. Zhubanov Aktobe Regional State University, Moldagulova Street 34, 030000 Aktobe, Kazakhstan \\ ${ }^{2}$ Dept. of Radio Electronics, T. Begeldinov Aktobe Aviation Inst., Moldagulova Street 39, 030012 Aktobe, Kazakhstan \\ serdau@rambler.ru, serdau@mail.ru
}

Submitted January 1, 2019 / Accepted September 26, 2019

\begin{abstract}
The nanostructures "Pt - TiO - Pt" and "Pt$\mathrm{NiO}$ - Pt" with weak switching properties and memory were studied within the framework of semi-empirical Hückel method. The calculation was implemented in the program Atomistix ToolKit with Virtual NanoLab. The transmission spectra, current-voltage characteristics and differential conductivity of nanostructures are calculated. It was revealed that in the range of voltages $-1.3 \mathrm{~V} \div 1.3 \mathrm{~V}$, a hysteresis appears in the form of eight shaped figure on the current-voltage characteristic of $\mathrm{Pt}-\mathrm{TiO}-\mathrm{Pt}$ nanostructure, and in Pt-NiO - Pt nanostructure, the hysteresis appears in the voltage intervals $-1.8 \mathrm{~V} \div 0.8 \mathrm{~V}$ and $0.9 \mathrm{~V} \div 1.8 \mathrm{~V}$ in the form of two oval-shaped figures connected to a segment. The manifestation of the hysteresis characteristic of these nanocontacts shows that they have memory. It was found that a negative differential resistance is observed in the voltage range, where the hysteresis of the current-voltage characteristic is appeared. It is shown that the investigating nanostructures have weak switching properties. The results of the paper can be useful for the calculation of memristic elements of nanoelectronics.
\end{abstract}

\section{Keywords}

Memristor, nanostructure, electron transport, currentvoltage characteristic, differential conductivity, transmission function (spectrum)

\section{Introduction}

At the end of 2008, the discovery of the effect of memrisivity in systems $\mathrm{Pt}-\mathrm{TiO}_{2}-\mathrm{Ti}_{n} \mathrm{O}_{2 n-1}-\mathrm{Pt}$, predicted back in 1971 by L. Chua, became a turning point in microelectronics [1-3]. It became clear that the effect of memrisivity arises in metal-dielectric nanocomposites due to the displacement of charges in a superthin dielectric layer when an electric field is applied. Increased interest in such nanostructures is associated with their use to create a new passive element of the electrical circuit - a memristor - a resistor with controlled resistance. Currently, the creation of switches, memory elements, constituent logic elements, oscillators, as well as modules of neural computers is being considered on the basis of memorial constructions [4-8]. In this regard, there is an intensive search for new metal-dielectric materials with memristic properties, as well as new models, describing their electrical characteristics [9], [10]. Various methods and modeling tools, such as SPICE (LTspice, Multisim and others), FEKO, Matlab, Verilog-A and others [11-15] have been developed to describe the memorial properties of various metal-dielectric materials.

In this paper, an attempt has been made to determine the main electrical characteristics of nanostructures of the type "Pt $-\mathrm{TiO}-\mathrm{Pt}$ " and " $\mathrm{Pt}-\mathrm{NiO}-\mathrm{Pt}$ " using the extended Hückel method [16].

\section{Description of the Object and Methods of Research}

The geometry of the studied nanocontacts is shown in Fig. 1, 2 (a), (b). The nanosystems under consideration consist of 306 atoms and have three regions with a total size $\sim 50 \AA$ : central region, left and right electrode areas. In the central region of $\mathrm{Pt}-\mathrm{TiO}-\mathrm{Pt}$ the active part of the nanodevice in the form of an oxide fragment of titanium consisting of 90 atoms is located, and in $\mathrm{Pt}-\mathrm{NiO}-\mathrm{Pt}$ there is nickel oxide consisting of 54 atoms, where the scattering of quasiparticles occurs in a region with a length of $\sim 8.78 \AA$ and $\sim 3.98 \AA$, respectively. Electrodes are obtained by expanding the central region along the $\mathrm{C}$ axis by $\sim 5.732 \AA$ and $\sim 8.6 \AA$. The distances between electrodes are $\sim 33.24 \AA(\mathrm{Pt}-\mathrm{TiO}-\mathrm{Pt})$ and $\sim 34.6 \AA(\mathrm{Pt}-\mathrm{NiO}-\mathrm{Pt})$, where the central region of the nanosystem is located.

Usually, optimization of such structures is well implemented using the ReaxFF potential (ReaxFF is Reactive Force Field), which is used to describe reactive processes [17]. In our case, the optimization of the nanostructures $\mathrm{Pt}-\mathrm{TiO}-\mathrm{Pt}$ is realized using the potential ReaxFF_CHONSiPtZrYBaTi_2013 [18], and of the nano- 


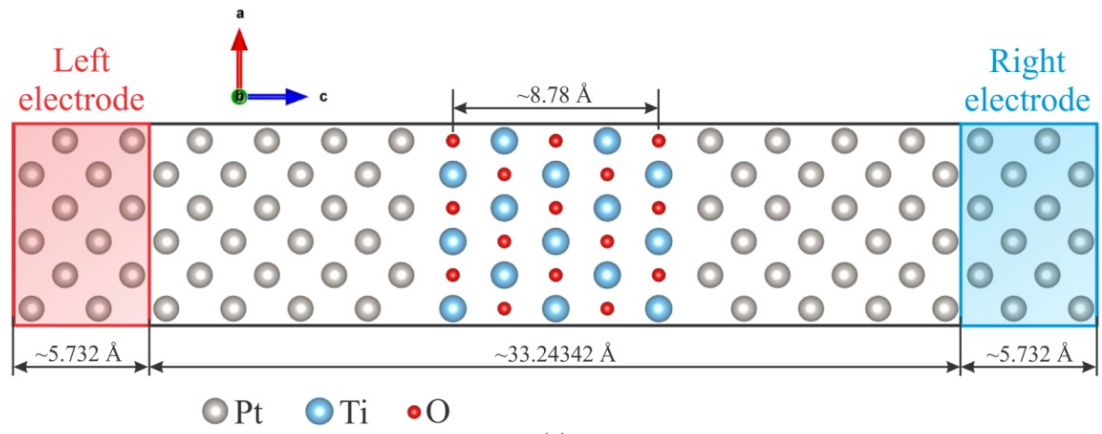

(a)

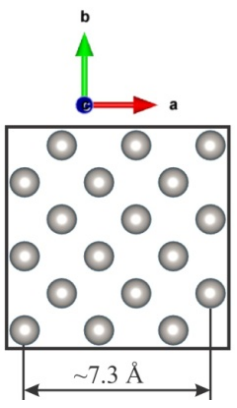

(b)

Fig. 1. The geometry of $\mathrm{Pt}-\mathrm{TiO}$ - Pt nanocontact: (a) ZX-plane; (b) ZY-plane.

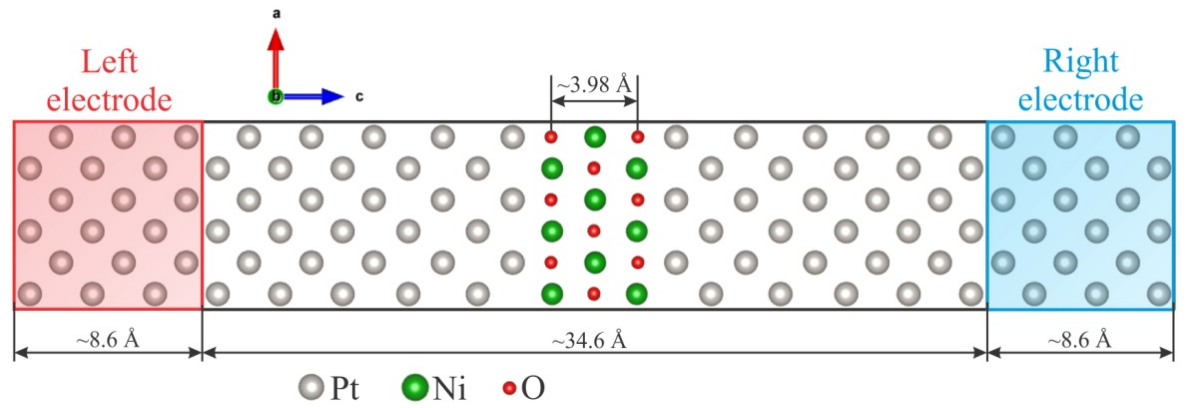

(a)

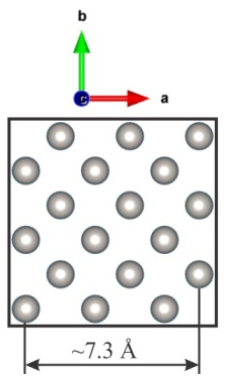

(b)

Fig. 2. The geometry of $\mathrm{Pt}-\mathrm{NiO}-\mathrm{Pt}$ nanocontact: (a) ZX-plane; (b) ZY-plane.

structures $\mathrm{Pt}-\mathrm{NiO}$ - Pt by ReaxFF_CHONSFPt-CINi_2010 [19]. At optimization of $\mathrm{Pt}-\mathrm{TiO}-\mathrm{Pt}$ structure the distance between atoms takes the following values: $\mathrm{Pt}-\mathrm{Pt}-\sim 2.482 \AA ; \mathrm{Ti}-\mathrm{Ti}-\sim 2.866 \AA ; \mathrm{O}-\mathrm{O}-\sim 2.866 \AA$; $\mathrm{Pt}-\mathrm{O}-\sim 2.2 \AA ; \mathrm{Ti}-\mathrm{O}-\sim 2.195 \AA ; \mathrm{Pt}-\mathrm{Ti}-\sim 2.99 \AA$. In the optimized structure of $\mathrm{Pt}-\mathrm{NiO}-\mathrm{Pt}$ nanocontact, the interatomic distances take the following values: $\mathrm{Pt}-\mathrm{Pt}-\sim 2.58 \AA ; \mathrm{Ni}-\mathrm{Ni}-\sim 2.85 \AA ; \mathrm{O}-\mathrm{O}-\sim 2.81 \AA$; $\mathrm{Pt}-\mathrm{O}-\sim 1.758 \AA ; \mathrm{Ni}-\mathrm{O}-\sim 2.02 \AA ; \mathrm{Pt}-\mathrm{Ni}-\sim 2.72 \AA$. (The distance and angles between atoms were determined using the VESTA program (Visualization for Electronic and STructural Analysis) [20]).

Computer simulation of the nanocontact was carried out within the framework of the extended Hückel method using the method of nonequilibrium Green's functions (NEGF - Non-Equilibrium Green's Functions) [16]. The calculation of electrotransport properties of the nanocontact consists of two stages. In the first stage, a self-consistent calculation is performed for platinum electrodes in the direction of the flow of electric current. In the second stage, the density matrices are determined, the density of real space is estimated, and the Hartree potential is calculated. A detailed description of this method can be found in [21-23].

To calculate the density matrix of the central region, firstly, a self-consistent calculation of the nanocontact left and right electrodes is performed and the corresponding Fermi levels are estimated: $\varepsilon_{\mathrm{L}}^{\mathrm{F}}$ and $\varepsilon_{\mathrm{R}}^{\mathrm{F}}$. Taking into account the bias voltage between two platinum electrodes, we determine the left and right chemical potentials:
$\mu_{\mathrm{L}}=\varepsilon_{\mathrm{L}}^{\mathrm{F}}-e V_{\text {bias }}$ and $\mu_{\mathrm{R}}=\varepsilon_{\mathrm{L}}^{\mathrm{F}}$. The applied bias voltage moves the quasiparticles from the left electrode to the right, thereby causing an electric current from left to right. The density matrix of the considered nonequilibrium system is represented as the sum of the density matrices of the left and right electrodes:

$$
\mathbf{D}=\mathbf{D}^{\mathrm{L}}+\mathbf{D}^{\mathrm{R}}
$$

where $\mathbf{D}^{\mathrm{L}}, \mathbf{D}^{\mathrm{R}}$ is density matrix of the left and right electrodes, respectively.

$$
\mathbf{D}^{\mathrm{L}}=\int \boldsymbol{\rho}^{\mathrm{L}}(\varepsilon) f\left(\frac{\varepsilon-\mu_{\mathrm{L}}}{k_{\mathrm{B}} T_{\mathrm{L}}}\right) \mathrm{d} \varepsilon
$$

where $\varepsilon$ is energy, $\rho^{\mathrm{L}}(\varepsilon)$ is spectral matrix, $f(\varepsilon)$ is Fermi energy distribution function of quasiparticles, $k_{\mathrm{B}}$ is Boltzmann constant, $\mu_{\mathrm{L}}$ is electrochemical potential, $T_{\mathrm{L}}$ is current temperature of the left electrode. Density matrix for the right electrode $\mathbf{D}^{\mathrm{R}}$ is found in a similar way. The spectral matrix is defined using the Green functions:

$$
\boldsymbol{\rho}^{\mathrm{L}}(\varepsilon)=\frac{1}{2 \pi} G(\varepsilon) \boldsymbol{\Gamma}^{\mathrm{L}}(\varepsilon) G^{\dagger}(\varepsilon)
$$

where $\Gamma^{\mathrm{L}}(\varepsilon)$ is broadening matrix (broadening function), $G(\varepsilon), G^{\dagger}(\varepsilon)$ is retarded and advanced Green's functions. The broadening matrix of the left electrode is described by the following equation:

$$
\Gamma^{\mathrm{L}}(\varepsilon)=\frac{1}{\mathrm{i}}\left(\sum^{\mathrm{L}}-\left(\sum^{\mathrm{L}}\right)^{\dagger}\right)
$$

where $\mathrm{i}$ is imaginary unit, $\Sigma^{\mathrm{L}}$ is self-energy of the left electrode. A similar equation exists for the density matrix of 
the right electrode. Green's retarded function is represented as

$$
G(\varepsilon)=\left[\left(\varepsilon+\mathrm{i} \delta_{+}\right) \mathbf{S}-\mathbf{H}-\sum^{\mathrm{L}}(\varepsilon)-\sum^{\mathrm{R}}(\varepsilon)\right]^{-1}
$$

where $\delta_{+}$is an infinitely small positive number, $\mathbf{S}$ is overlap integral matrix, $\mathbf{H}$ is Hamiltonian matrix.

After obtaining a self-consistent one-electron Hamiltonian, the transmission function of the nanostructures under consideration is determined, which is then used to determine its current-voltage characteristic (CVC) and differential conductivity. The fraction of the scattering state $k$, propagating through the structure, is determined by the transmission amplitude $t_{k}$, then the transmission coefficient at energy $\varepsilon$ is determined by summing the transmission amplitude $t_{k}$ from all states at this energy:

$$
T(\varepsilon)=\sum_{k} t_{k}^{\dagger} t_{k} \delta\left(\varepsilon-\varepsilon_{k}\right)
$$

where $\varepsilon$ is energy, $t_{k}$ is transmission amplitude, $\delta(\varepsilon)$ is delta function. Using (4)-(6), the transmission spectrum can be calculated by the expression:

$$
T(\varepsilon)=\operatorname{tr}\left[\boldsymbol{\Gamma}^{\mathrm{L}} G \boldsymbol{\Gamma}^{\mathrm{R}} G^{\dagger}\right]=\operatorname{tr}\left[\boldsymbol{\Gamma}^{\mathrm{R}} G \boldsymbol{\Gamma}^{\mathrm{L}} G^{\dagger}\right] .
$$

The current flowing through the nanocontact is determined on the basis of the well-known Landauer equation, which indicates the fundamental connection of the electric current with the transmission spectrum:

$$
I=\frac{2 e}{h} \int_{-\infty}^{+\infty} T(\varepsilon)\left[f\left(\frac{\varepsilon-\mu_{\mathrm{R}}}{k_{\mathrm{B}} T_{\mathrm{R}}}\right)-f\left(\frac{\varepsilon-\mu_{\mathrm{L}}}{k_{\mathrm{B}} T_{\mathrm{L}}}\right)\right] \mathrm{d} \varepsilon
$$

where $e$ is electron charge, $h$ is Planck's constant, $T_{\mathrm{R}}, T_{\mathrm{L}}$ are current temperatures and $\mu_{\mathrm{R}}, \mu_{\mathrm{L}}$ are chemical potentials of the right and left electrode.

The transconductance estimate is obtained by calculating a self-consistent current at a number of applied bias voltages $V_{\text {bias }}^{1}, V_{\text {bias }}^{2}, \ldots$, and performing numerical differentiation according to the formula

$$
\sigma\left(V_{\text {bias }}, T_{\mathrm{L}}, T_{\mathrm{R}}\right)=\frac{I\left(V_{\text {bias }}^{1}, T_{\mathrm{L}}, T_{\mathrm{R}}\right)-I\left(V_{\text {bias }}^{2}, T_{\mathrm{L}}, T_{\mathrm{R}}\right)}{V_{\text {bias }}^{1}-V_{\text {bias }}^{2}} .
$$

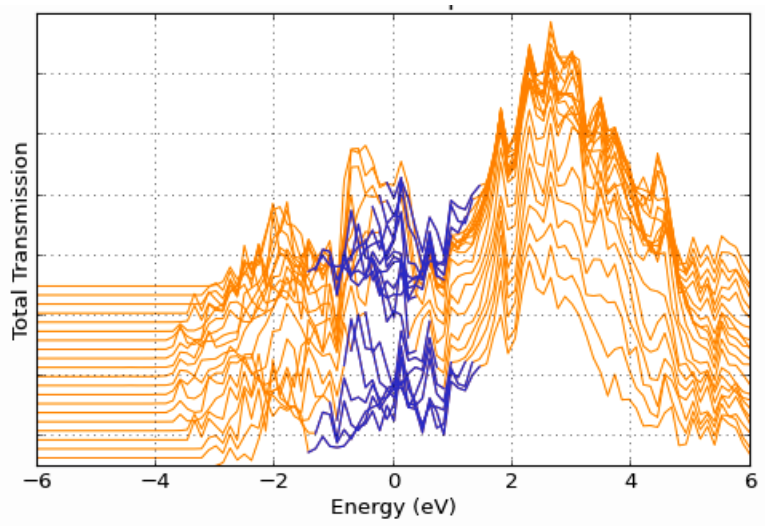

(a)

\section{Description and Analysis of Results}

The results of computer simulations of the transmission spectra, CVC, and differential conductivity of "Pt $-\mathrm{TiO}-\mathrm{Pt}$ " and "Pt $-\mathrm{NiO}-\mathrm{Pt}$ " nanostructures are shown in Fig. 3, 4.

The features of the transmission spectrum of $\mathrm{Pt}-\mathrm{TiO}-\mathrm{Pt}$ nanocontact are observed in the energy interval $-3.6 \div 6 \mathrm{eV}$ (Fig. 3a). The transmission spectrum maxima in the absence of a bias voltage are observed at energies $-3.6 \mathrm{eV},-3.12 \mathrm{eV},-1.8 \mathrm{eV},-1.44 \mathrm{eV},-1.08 \mathrm{eV}$, $-0.48 \mathrm{eV}, 0.12 \mathrm{eV}, 0.6 \mathrm{eV}, 1.08 \mathrm{eV}, 2.28 \mathrm{eV}, 2.64 \mathrm{eV}$, $3.0 \mathrm{eV}, 3.48 \mathrm{eV}, 3.72 \mathrm{eV}, 4.44 \mathrm{eV}$ and $5.52 \mathrm{eV}$.

The deviation from the constant value of the transmission spectrum of $\mathrm{Pt}-\mathrm{NiO}-\mathrm{Pt}$ nanocontact is observed in the energy range $-4.2 \mathrm{eV} \div 0 \mathrm{eV}$ (Fig. $3 \mathrm{~b}$ ). The maxima of the transmission spectrum of a nanocontact in the absence of a bias voltage are observed at energies $-3.72 \mathrm{eV}$, $-3.36 \mathrm{eV},-2.4 \mathrm{eV},-2.04 \mathrm{eV},-1.68 \mathrm{eV},-1.2 \mathrm{eV},-0.96 \mathrm{eV}$, $-0.36 \mathrm{eV},-0.12 \mathrm{eV}$.

The transmission spectra of the being examined system with distinct maxima resemble the spectrum of resonant tunnel structures [24]. This may be due to the low dimension of the central region of the nanosystem consisting of a fragment of titanium and nickel oxides with sizes $\sim 8.78 \AA$ and $\sim 3.98 \AA$, respectively (Fig. 1, 2).

Figure 4 shows the dependence of the transmission spectrum of $\mathrm{Pt}-\mathrm{TiO}-\mathrm{Pt}$ nanocontact on $k$ at various energy values. At energy $-1.32 \mathrm{eV}$, the spectrum has minima with the following combinations of $k_{\mathrm{A}}, k_{\mathrm{B}}$ : $(0.012$; $0.2) ;(-0.2 ; 0.0011) ;(-0.0012 ;-0.2)$ and $(0.2 ;-0.0011)$.

Further, at $-0.96 \mathrm{eV}$, the indicated spectrum minima remain, however, its maximum at 8.4 arbitrary units is observed at $k_{\mathrm{A}}=0.0012$ and $k_{\mathrm{B}}=-0.0011$ (Fig. $4 \mathrm{~b}$ ). At zero energy, four minima disappear, the maximum remains at the center of dependence $T(k)$.

Further, the peak of the function $T(k)$ begins to shift from the center to the edge and at $3.48 \mathrm{eV}$ the minimum value of the transmission spectrum appears at $k_{\mathrm{A}}=0.0012$

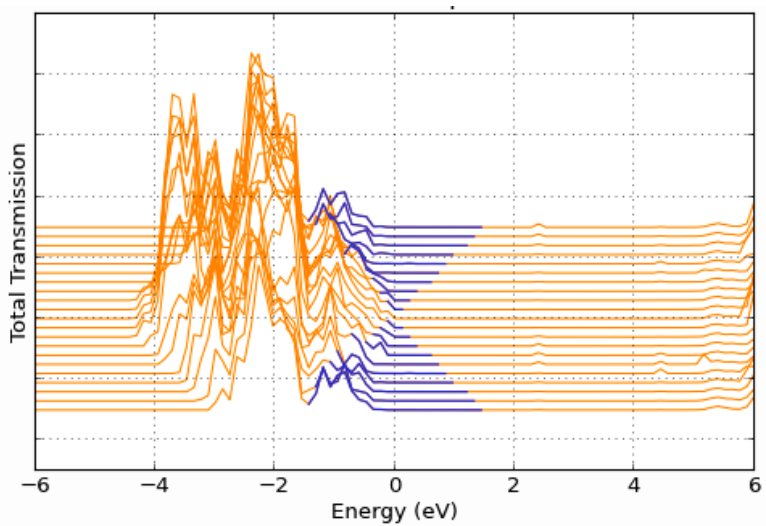

(b)

Fig. 3. Evolution of the transmission spectra of "Pt - $\mathrm{TiO}-\mathrm{Pt}$ " (a) and "Pt $-\mathrm{NiO}-\mathrm{Pt}$ " (b) nanocontacts with an increase in the bias voltage $\mathrm{V}_{\text {bias }}$ from $-3 \mathrm{~V}$ to $3 \mathrm{~V}$. 


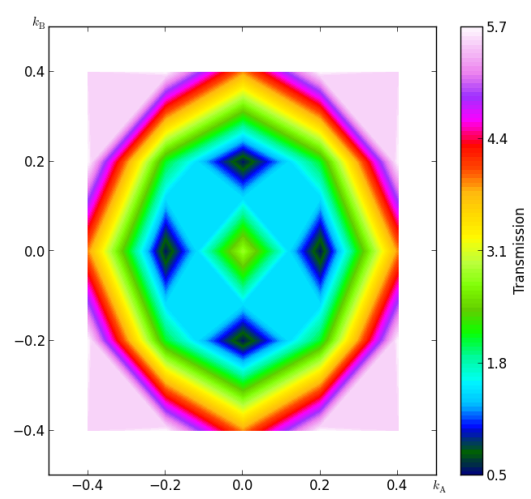

(a)

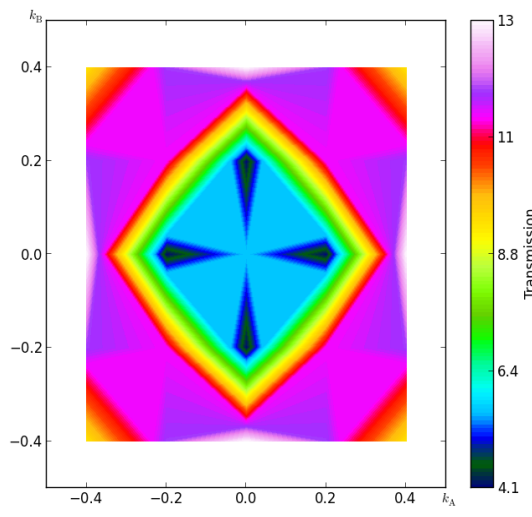

(d)

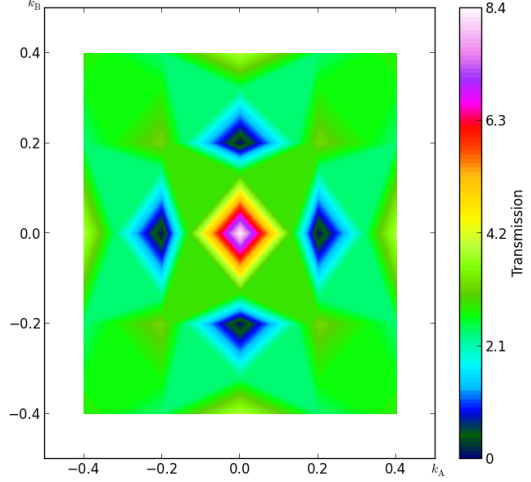

(b)

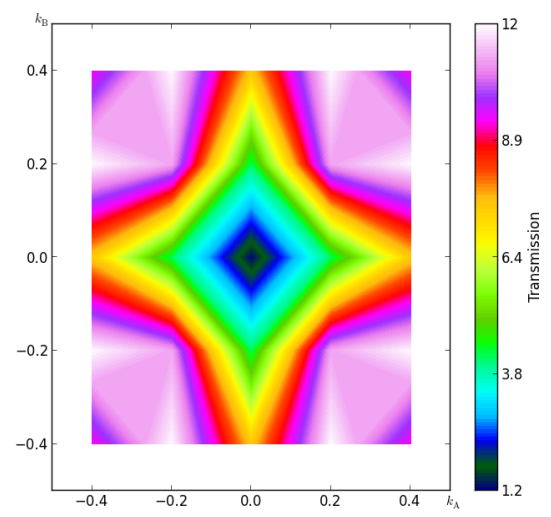

(e)

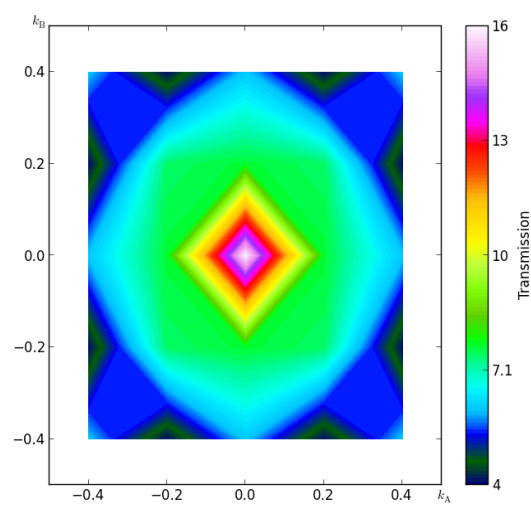

(c)

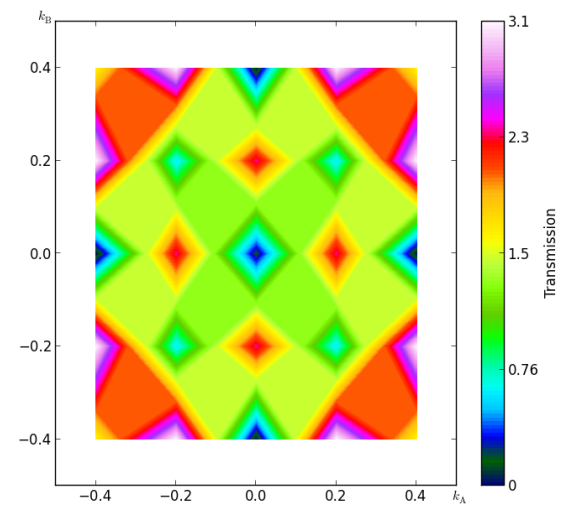

(f)

Fig. 4. Evolution of the transmission spectrum $T(k)$ of $\mathrm{Pt}$ - TiO - Pt nanocontacts with a change in energy: (a) $-1.32 \mathrm{eV}$; (b) $-0.96 \mathrm{eV}$; (c) $0 \mathrm{eV}$; (d) $2.88 \mathrm{eV}$; (e) $3.48 \mathrm{eV}$; (f) $5.52 \mathrm{eV}$.

and $k_{\mathrm{B}}=-0.0011$. As can be seen, the transmission spectrum of the structure is an oscillating function.

Figure 5 shows the evolution of the transmission spectrum of $\mathrm{Pt}-\mathrm{NiO}-\mathrm{Pt}$ nanocontact from $k$ with a change in energy. As can be seen from Fig. 3(b) the oscillation of the transmission spectrum occurs in the energy interval $-4.2 \mathrm{eV} \div 0 \mathrm{eV}$; therefore, we consider the dependence $T(k)$ in this energy interval. At $-4.2 \mathrm{eV}$, four localized maxima of the spectrum are observed (Fig. 5a). With increasing energy up to $-2.4 \mathrm{eV}$, the peak values of the spectrum accumulate at the center of the dependence $T(k)=14$ arb. units at $k_{\mathrm{A}}=k_{\mathrm{B}}=0$. Further, the maxima of $T(k)$ function begin to shift from the center to the edge and at $-1.2 \mathrm{eV}$ the minimum value of the spectrum is observed at $k_{\mathrm{A}}=k_{\mathrm{B}}=0$.

The results of simulation of current-voltage characteristics $(\mathrm{CVC})$ and differential conductivity are shown in Fig. 6. (The solid curve describes the characteristics of the direct connection of nanocontacts to the power source, and the dotted one - on the reverse inclusion.)

In the voltage range of $-1.3 \mathrm{~V} \div 1.3 \mathrm{~V}$, when directly connected and changing the polarity, the CVC characteristic of $\mathrm{Pt}-\mathrm{TiO}-\mathrm{Pt}$ nanocontact acquires a shape of eight number (inherent in memristic elements). However, with further voltage variation, no hysteresis of the current-voltage characteristic is observed (Fig. 6(a)).
The differential conductivity of such nanosystem has a peak structure, and when directly turned on, its maxima of $260 \mu \mathrm{S}, 60 \mu \mathrm{S}, 120 \mu \mathrm{S}$ are observed at values of a bias voltage of $0 \mathrm{~V}, \pm 1.4 \mathrm{~V}, \pm 2.6 \mathrm{~V}$, respectively. The minima of the $\mathrm{d} I / \mathrm{d} V$ spectrum of the nanosystem $-30 \mu \mathrm{S}$ and $20 \mu \mathrm{S}$ occur as "dips" at bias voltages of $\pm 1 \mathrm{~V}, \pm 1.8 \mathrm{~V}$, respectively. When the nanocontact is switched back on, the "large peak" of conductivity splits into two $222 \mu \mathrm{S}$ and $250 \mu \mathrm{S}$ at voltages of $-1.1 \mathrm{~V}$ and $1.2 \mathrm{~V}$, respectively (Fig. 6a).

The hysteresis of the CVC of $\mathrm{Pt}-\mathrm{NiO}-\mathrm{Pt}$ nanocontact is observed in the voltage range of $-1.8 \mathrm{~V} \div 0.8 \mathrm{~V}$ and $0.9 \mathrm{~V} \div 1.8 \mathrm{~V}$ in the form of an oval shape (Fig. $6 \mathrm{~b}$ ). Outside the specified voltage range, the amount of current flowing through the contact is the same in both direct and reverse connection.

At direct and reverse switching of the nanocontact, the maxima of the differential conductivity of $300 \mu \mathrm{S}$ and $270 \mu \mathrm{S}$ appear at a bias voltage of $-2 \mathrm{~V}$ and $2.1 \mathrm{~V}$, respectively, also "secondary" peaks $110 \mu \mathrm{S}$ and $125 \mu \mathrm{S}$ occur at $\pm 1.05 \mathrm{~V}$.

Differential conductivity dips are observed at $-2.6 \mathrm{~V}$ $(-12 \mu \mathrm{S}),-1.6 \mathrm{~V}(-70 \mu \mathrm{S}), 1.6 \mathrm{~V}(-30 \mu \mathrm{S}), 2.4 \mathrm{~V}(36 \mu \mathrm{S})$. At reverse switching, a shift in dips of $-1.4 \mathrm{~V}(-50 \mu \mathrm{S})$, $1.45 \mathrm{~V}(-20 \mu \mathrm{S})$ is observed.

As can be seen from Fig. 6(a), (b), on the characteristics of both nanocontacts, a negative differential resistance 


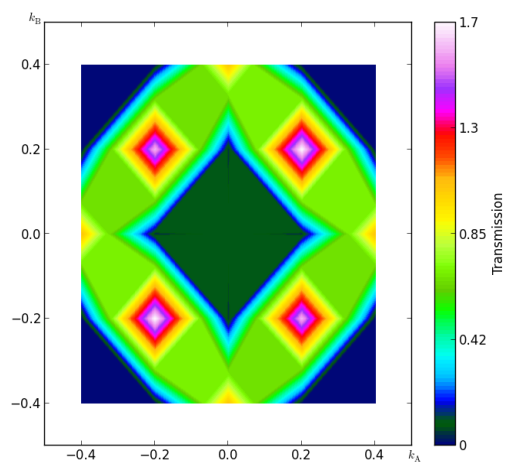

(a)

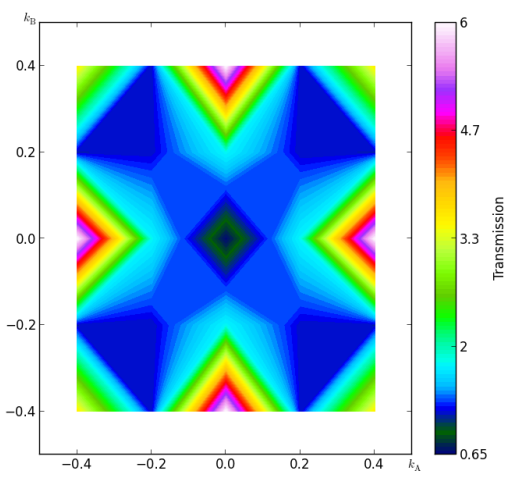

(d)

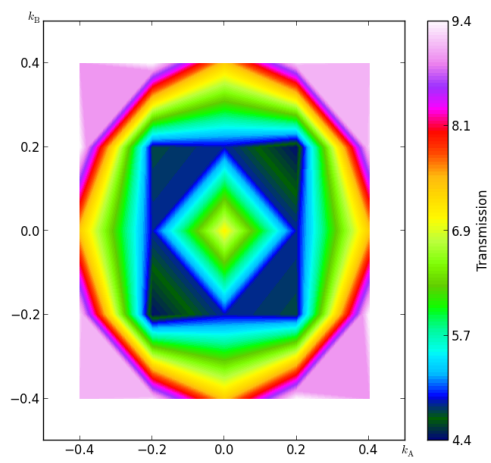

(b)

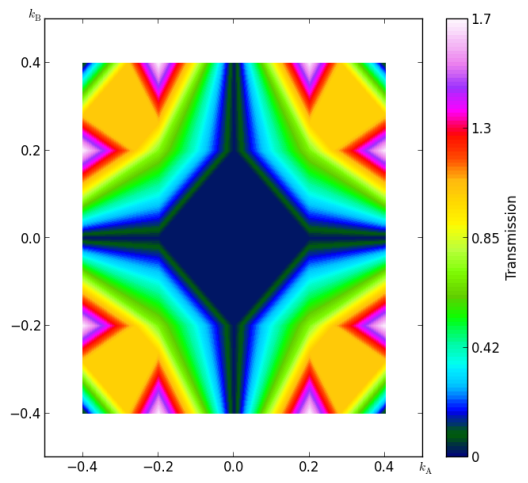

(e)

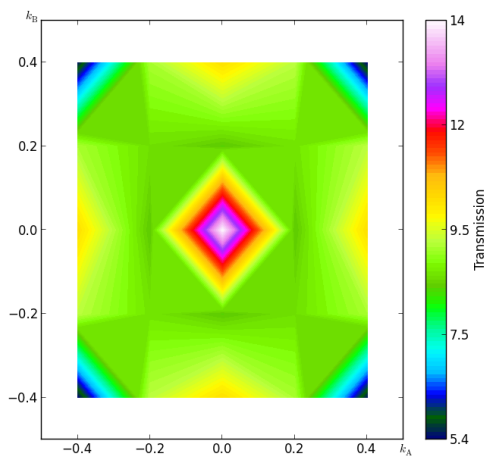

(c)

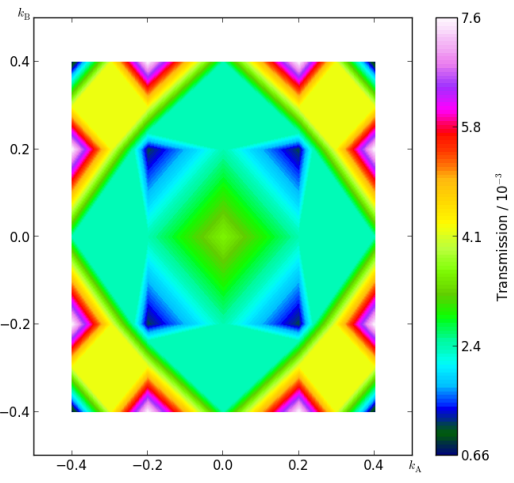

(f)

Fig. 5. Evolution of the transmission spectrum $T(k)$ of $\mathrm{Pt}-\mathrm{NiO}$ - Pt nanocontacts with a change in energy: (a) $-4.2 \mathrm{eV}$; (b) $-3.36 \mathrm{eV}$; (c) $-2.4 \mathrm{eV}$; (d) $-1.2 \mathrm{eV}$; (e) $-0.36 \mathrm{eV}$; (f) $0 \mathrm{eV}$.

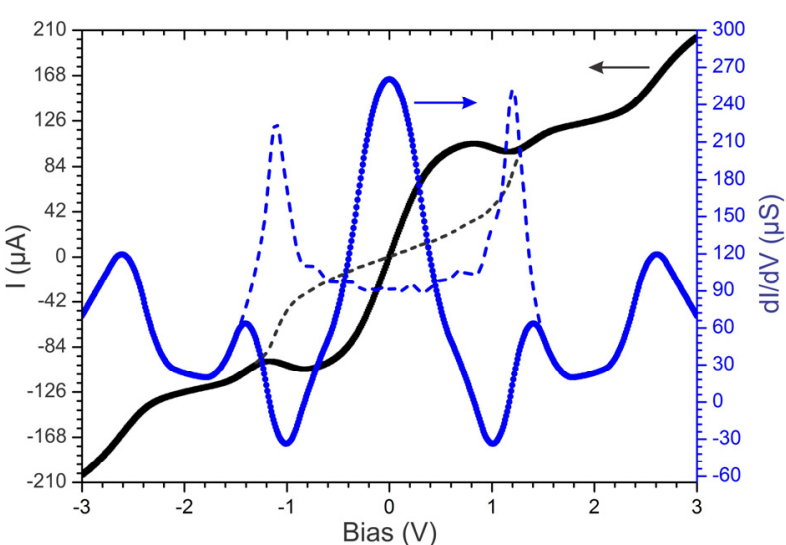

(a)

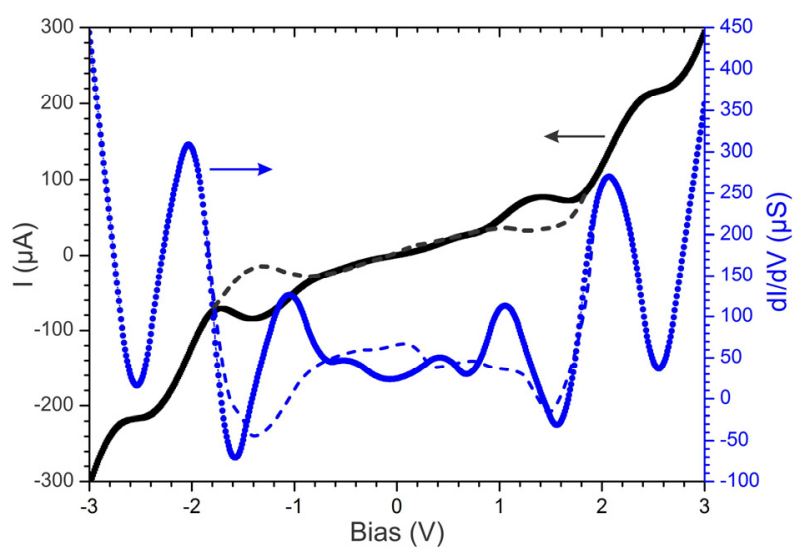

(b)

Fig. 6. Current-voltage and $\mathrm{d} / / \mathrm{d} V$ characteristics of $\mathrm{Pt}-\mathrm{TiO}-\mathrm{Pt}$ (a) and $\mathrm{Pt}-\mathrm{NiO}-\mathrm{Pt}$ (b) nanocontacts: solid curve - direct connection, dashed - reverse connection.

is observed in the voltage range, where the hysteresis of the CVC is appeared.

Observation of the hysteresis characteristics of these nanocontacts shows that they have memory. Also, from the current-voltage characteristics of the structures, it can be seen that the investigated objects have weak switching properties (Fig. 6). For example, at reverse connection of $\mathrm{Pt}-\mathrm{TiO}-\mathrm{Pt}$ nanocontact in the voltage range of $-0.86 \mathrm{~V} \div 1 \mathrm{~V}$, a rapid linear change in the current value from $-42 \mu \mathrm{A}$ to $42 \mu \mathrm{A}$ is observed, and in the case of $\mathrm{Pt}-\mathrm{NiO}-\mathrm{Pt}$ nanocontact, switching from ON mode to OFF occurs at voltages of $-0.88 \mathrm{~V}$ and $0.85 \mathrm{~V}$.
Figure 7 shows the hysteresis of the CVC and the change in the resistance of the channels of nanocontacts depending on the bias voltage. As can be seen, at the beginning of the formation of hysteresis, the CVC of the nanocontacts of the channel resistances for direct and reverse connection are $\left(R_{\text {d.c. } 0} \approx R_{\text {r.c. } 0}\right)$.

At the case of nanocontact $\mathrm{Pt}-\mathrm{TiO}-\mathrm{Pt}$ : $R_{\text {d.c. } 0} \approx R_{\text {r.c. } 0} \approx 12.9 \mathrm{k} \Omega$. At direct switching of nanocontact $\mathrm{Pt}-\mathrm{TiO}-\mathrm{Pt}$ in the interval of $V_{\text {bias }}$ from $-1.3 \mathrm{~V}$ to $0 \mathrm{~V}$ channel resistance decreases exponentially to several ohms, then in the interval $V_{\text {bias }}$ from $0 \mathrm{~V}$ to $1.3 \mathrm{~V}$ its value is restored (Fig. 7 a). At reverse switching of nanocontact in the 


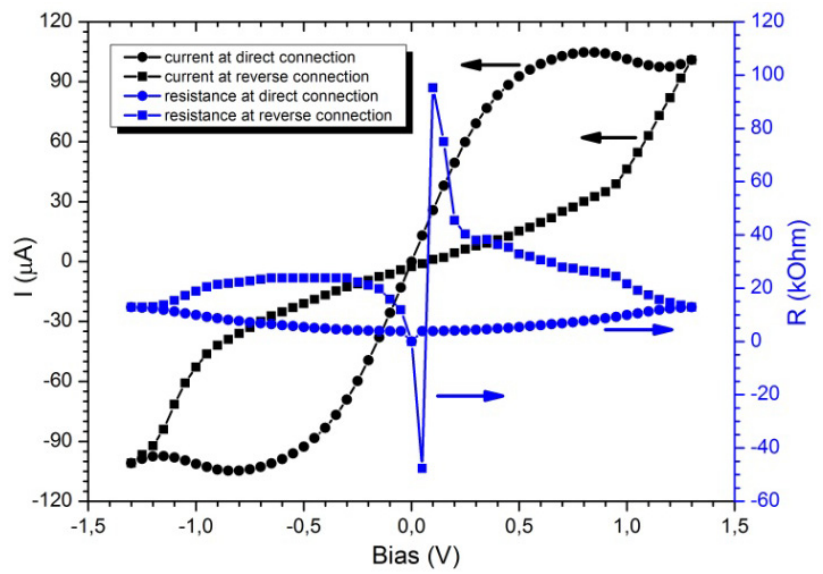

(a)

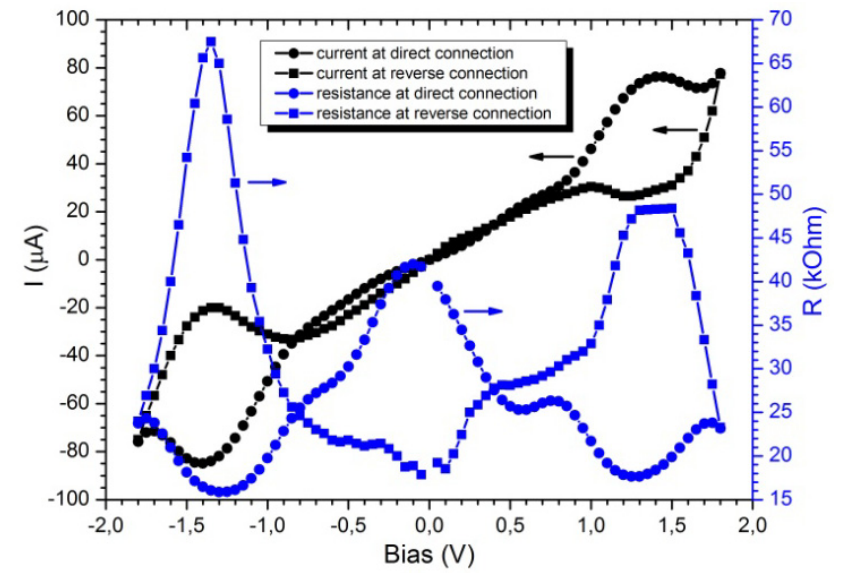

(b)

Fig. 7. CVC hysteresis and changes in the resistance of nanocontact channels $\mathrm{Pt}-\mathrm{TiO}-\mathrm{Pt}(\mathrm{a})$ and $\mathrm{Pt}-\mathrm{NiO}-\mathrm{Pt}(\mathrm{b})$.

interval of $V_{\text {bias }}$ from $-1.3 \mathrm{~V}$ to $0.1 \mathrm{~V}$ resistance increases to $95.24 \mathrm{k} \Omega$. Then there is a sharp decrease in channel resistance and at the same time the completion of the first loop of the CVC. A similar inverse process of resistance behavior during reverse switching occurs in the interval of $V_{\text {bias }}$ from $0 \mathrm{~V}$ to $-1.3 \mathrm{~V}$, forming the second loop of CVC.

At the beginning of the formation of hysteresis of the $\mathrm{CVC}$ of the nanocontact $\mathrm{Pt}-\mathrm{NiO}-\mathrm{Pt}$ the resistances $R_{\text {d.c. } 0} \approx R_{\text {r.c. } 0} \approx 23.74 \mathrm{k} \Omega \div 24 \mathrm{k} \Omega$. At direct switching of the nanocontact in the interval $V_{\text {bias }}$ from $-1.8 \mathrm{~V}$ to $-1.3 \mathrm{~V}$ channel resistance decreases to $16 \mathrm{k} \Omega$, then in the interval of $V_{\text {bias }}$ from $-1.3 \mathrm{~V}$ to $-0.1 \mathrm{~V}$ its value increases to $\sim 41 \mathrm{k} \Omega$ (Fig. 7b). Further, the reverse quasi-symmetric behavior of the resistance is observed with a minimum value of $\sim 18 \mathrm{k} \Omega$ and at $V_{\text {bias }} \approx 1.8 \mathrm{~V}$ the final resistances at direct and reverse switching are equal to $R_{\text {d.c. } 1} \approx R_{\text {r.c. } 1} \approx 23.2 \mathrm{k} \Omega$. At the reverse switching of nanocontact to $V_{\text {bias }} \approx 1.3 \mathrm{~V}$, the channel resistance increases sharply, forming the maximum value of the first hysteresis loop of the CVC due to the significant difference in resistance $\Delta R=\left|R_{\text {d.c. }}-R_{\text {r.c. }}\right| \approx$ $30.48 \mathrm{k} \Omega$. Then the channel resistance decreases to $17 \mathrm{k} \Omega$ at a near-zero bias voltage value. At $V_{\text {bias }} \approx 0.7 \mathrm{~V}$, the formation of the first hysteresis loop of the $\mathrm{CVC}$ is completed. Then, in the range of $V_{\text {bias }}$ from $-0.1 \mathrm{~V}$ to $-1.35 \mathrm{~V}$, an increase in channel resistance is observed. At $V_{\text {bias }} \approx-0.8 \mathrm{~V}$, the resistances $R_{\text {d.c. } 0} \approx R_{\text {r.c. } 0} \approx 25 \mathrm{k} \Omega$ and the second $\mathrm{CVC}$ loop is formed. The growth of the channel resistance stops after reaching the maximum value of $65.7 \mathrm{k} \Omega$ at $V_{\text {bias }} \approx$ $-1.35 \mathrm{~V}$. In this case, the value $\Delta R \approx 51.43 \mathrm{k} \Omega$ assumes the maximum value, which is reflected in the hysteresis of the CVC.

\section{Conclusion}

Thus, in this work, the basic electric transport characteristics (transmission spectra, CVC, differential conductivity) of $\mathrm{Pt}-\mathrm{TiO}-\mathrm{Pt}$ and $\mathrm{Pt}-\mathrm{NiO}-\mathrm{Pt}$ nanocontacts were investigated within the framework of the semi-em- pirical extended Hückel method. It was shown that in the voltage range $-1.3 \mathrm{~V} \div 1.3 \mathrm{~V}$, the $\mathrm{CVC}$ of $\mathrm{Pt}-\mathrm{TiO}-\mathrm{Pt}$ nanostructure has a number eight shape hysteresis, and the hysteresis of the $\mathrm{CVC}$ of $\mathrm{Pt}-\mathrm{NiO}-\mathrm{Pt}$ nanostructure manifests itself in voltage intervals $-1.8 \mathrm{~V} \div 0.8 \mathrm{~V}$ and $0.9 \mathrm{~V} \div 1.8 \mathrm{~V}$ in the form of two oval-shaped figures, connected to a segment. Observation of the hysteresis characteristics of these nanocontacts shows that they have memory. It was found that the "large peak" of the differential conductivity of $\mathrm{Pt}-\mathrm{TiO}-\mathrm{Pt}$ nanocontact at the reverse switching of the conductivity splits into two $222 \mu \mathrm{S}$ and $250 \mu \mathrm{S}$ at voltages of $-1.1 \mathrm{~V}$ and $1.2 \mathrm{~V}$. It is shown that negative differential resistance is observed in the voltage range, where the hysteresis of the current-voltage characteristic is appeared. The evolution of the transmission spectrum of the nanostructure with an increase in the bias voltage (from $-3 \mathrm{~V}$ to $3 \mathrm{~V}$ ) is presented. It is shown that an increase in the difference in the resistance of the channels of nanocontacts increases the hysteresis of their CVC. The results of the paper may be useful for the calculation of new promising memorial elements of nanoelectronics.

\section{References}

[1] CHUA, L. If it's pinched it's a memristor. Semiconductor Science and Technology, 2014, vol. 29, no. 10, p. 1-42. DOI: 10.1088/0268-1242/29/10/104001

[2] STRUKOV, D. B., SNIDER, G. S., STEWART, D. R., et al. The missing memristor found. Nature, 2008, vol. 453, p. 80-83. DOI: 10.1038 /nature 06932

[3] CHUA, L. Memristor - the missing circuit element. IEEE Transactions on Circuit Theory, 1971, vol. 18, no. 5, p. 507-519. DOI: 10.1109/TCT.1971.1083337

[4] BESSONOV, A. A., KIRIKOVA, M. N., PETUKHOV, D. I., et al. Layered memristive and memcapacitive switches for printable electronics. Nature Materials, 2015, vol. 14, no. 2, p. 199-204. DOI: 10.1038/NMAT4135

[5] PREZIOSO, M., MERRIKH BAYAT, F., HOSKINS, B., et al. Self-adaptive spike-time-dependent plasticity of metal-oxide 
memristors. Scientific Reports, 2016, vol. 6, p. 1-6. DOI: $10.1038 /$ srep21331

[6] EBONG, I. E., MAZUMDER, P. Self-controlled writing and erasing in a memristor crossbar memory. IEEE Transactions on Nanotechnology, 2011, vol. 10, p. 1454-1463. DOI: 10.1109/TNANO.2011.2166805

[7] MOSAD, A. G., FOUDA, M. E., KHATIB, M. A., et al. Improved memristor-based relaxation oscillator. Microelectronics Journal, 2013, vol. 44, no. 9, p. 814-820. DOI: 10.1016/j.mejo.2013.04.005

[8] INDIVERI, G., LINARES-BARRANCO, B., LEGENSTEIN, R., et al. Integration of nanoscale memristor synapses in neuromorphic computing architectures. Nanotechnology, 2013, vol. 24, no. 38, p. 1-13. DOI: $10.1088 / 0957-4484 / 24 / 38 / 384010$

[9] ADAMATZKY, A., CHUA, L. (Eds.) Memristor Networks. ChamHeidelberg-New York-Dordrecht-London: Springer, 2014, p. 720. DOI: $10.1007 / 978-3-319-02630-5$

[10] ASCOLI, A., TETZLAFF, R., CHUA, L. Robust simulation of a TaO memristor model. Radioengineering, 2015, vol. 24, no. 2, p. 384-392. DOI: 10.13164/re.2015.0384

[11] BIOLEK, Z., BIOLEK, D., BIOLKOVÁ, V. SPICE model of memristor with nonlinear dopant drift. Radioengineering, 2009, vol. 18 , no. 2 , p. $210-214$. ISSN: $1210-2512$

[12] YANG, CH., CHOI, H., PARK, S., SAH, M. P., KIM, H., CHUA, L. O. A memristor emulator as a replacement of a real memristor. Semiconductor Science and Technology, 2015, vol. 30, no. 1, p. 1-9. DOI: 10.1088/0268-1242/30/1/015007

[13] SINGH, J., RAJ, B. Comparative analysis of memristor models and memories design. Journal of Semiconductors, 2018, vol. 39, no. 7, p. 1-12. DOI: 10.1088/1674-4926/39/7/074006

[14] RZIGA, F. O., MBAREK, K., GHEDIRA, S., et al. The basic I-V characteristics of memristor model: simulation and analysis. Applied Physics A, 2017, vol. 123, p. 1-8. DOI: 10.1007/s00339017-0902-9

[15] POTREBIC, M., TOSIC, D. Application of memristors in microwave passive circuits. Radioengineering, 2015, vol. 24, no. 2 , p. $408-419$. DOI: $10.13164 /$ re.2015.0408

[16] STOKBro, K., PETERSEN, D. E., SMidSTRUP, S., et al. Semiempirical model for nanoscale device simulations. Physical Review B, 2010, vol. 82, no. 7, p. 1-7. DOI: 10.1103/PhysRevB.82.075420

[17] VAN DUIN, A. C. T., DASGUPTA, S., LORANT, F., et al. ReaxFF: A reactive force field for hydrocarbons. Journal of Physical Chemistry A, 2001, vol. 105, no. 41, p. 9396-9409. DOI: 10.1021/jp004368u
[18] NASERIFAR, S., LIU, L., GODDARD, W. A., et al. Toward a process-based molecular model of $\mathrm{SiC}$ membranes. 1. Development of a reactive force field. Journal of Physical Chemistry C, 2013, vol. 117, no. 7, p. 3308-3319. DOI: $10.1021 /$ jp3078002

[19] MUEller, J. E., VAN DUIN, A. C. T., GODDARD, W. A. Development and validation of ReaxFF reactive force field for hydrocarbon chemistry catalyzed by nickel. Journal of Physical Chemistry C, 2010, vol. 114, no. 11, p. 4939-4949. DOI: $10.1021 /$ jp9035056

[20] MOMMA, K., IZUMI, F. VESTA 3 for three-dimensional visualization of crystal, volumetric and morphology data. Journal of Applied Crystallography, 2011, vol. 44, no. 6, p. 1272-1276. DOI: $10.1107 / \mathrm{S} 0021889811038970$

[21] SERGEYEV, D., TUMYSHEV, N. About coherent electron transport in nanocontacts " $\mathrm{Nb}$ - DNA - Nb". Journal of Nanoand Electronic Physics, 2018, vol. 10, no. 5, p. 1-5. DOI: 10.21272/jnep.10(5).05027 (in Russian)

[22] SERGEYEV, D., SHUNKEYEV, K. Investigation of transport parameters of graphene-based nanostructures. Russian Physics Journal, 2018, vol. 60, no. 11, p. 1938-1945. DOI: $10.1007 / \mathrm{s} 11182-018-1306-9$

[23] SERGEYEV, D. Computer simulation of electrical characteristics of a graphene cluster with stone-wales defects. Journal of Nanoand Electronic Physics, 2018, vol. 10, no. 3, p. 1-5. DOI: 10.21272/jnep.10(3).03018 (in Russian)

[24] DATTA, S. Quantum Transport: Atom to Transistor. Cambridge University Press, 2005, p. 404. ISBN-13: 978-0521631457. DOI: $10.1017 /$ CBO9781139164313

\section{About the Authors ...}

Daulet SERGEYEV was born in Kazakhstan, Aktobe, Ph.D., associate professor. He has defended his Ph.D. thesis in 2010. His research interests include modeling of physical processes in solids, nanoelectronics, superconducting electronics, Josephson effect, Andreev reflection, point defects study.

Nurgul ZHANTURINA was born in Kazakhstan, Uralsk, Ph.D. She has defended her Ph.D. thesis in 2014. Her research interests include dynamics of excitons state in solids, electronic excitations in dielectrics, theoretical modeling of physical processes in solids, luminescence. 